\title{
Conduct problems in young, school-going children in Ireland: Prevalence and teacher response
}

School Psychology International 2014, Vol. 35(5) 516-529

(C) The Author(s) 2013

Reprints and permissions: sagepub.co.uk/journalsPermissions.nav DOI: $10.1177 / 0143034313515984$ spi.sagepub.com

\section{Lynda Hyland and Grainne Ní Mháille}

National University of Ireland, Maynooth, Ireland

\section{Anne Lodge}

Church of Ireland College of Education, Ireland

\section{Sinead McGilloway}

National University of Ireland, Maynooth, Ireland

\begin{abstract}
Conduct problems in school settings can pose significant challenges for both children and teachers. This study examined the teacher-reported prevalence of conduct problems in a sample of young children $(N=445)$ in the first two years of formal education. A secondary aim was to assess teachers' perceptions of child behaviour and their classroom management strategies. The study was undertaken in II schools located in south west Ireland. Overall, children displayed positive socio-emotional and behavioural adjustment, although more than one-quarter had difficulties outside the 'normal' range. Class size and gender were shown to play a role in the level of difficulties experienced. Teachers reported significant challenges in managing classroom behavioural problems. This study provides some useful insights into the socio-emotional and behavioural needs of school-entry age children. The findings also have important policy and practice implications for school psychologists and other key school personnel and highlight, in particular, the need to develop and implement early intervention and prevention strategies in schools.
\end{abstract}

\section{Keywords}

Adjustment to school, conduct problems, emotional and behavioural difficulties, prevalence, teacher classroom management

\section{Corresponding author:}

Sinead McGilloway, Department of Psychology, NUI Maynooth, Maynooth, Ireland.

Email: Sinead.McGilloway@nuim.ie 
The early school years represent a time of considerable transition. Rapid physical and psychological development during this period is accompanied by a need to develop academic skills, such as motivation and attention to schoolwork and classroom instructions (Stephen \& Cope, 2003). Socio-emotional skills are also important in helping children to learn to interact appropriately with teachers and peers, necessitating the development of effective coping strategies and self-regulation capabilities (Blair \& Diamond, 2008).

Conduct problems in childhood have been shown to impact negatively on children's academic lives and may result in poor educational performance, school disengagement, absenteeism and early school leaving (Barbarin, 2007; Evans, Harden, Thomas, \& Benefield, 2003). Children with conduct problems or social, emotional, and behavioural difficulties are also much more likely to experience negative relationships with teachers and peers and are at greater risk of depressed mood and low self-esteem (Ladd, 1990). Socio-emotional dysregulation and behavioural maladjustment in early childhood can increase the risk of delinquency, psychopathology, substance abuse, social welfare dependency, and poor adult relationships later in life (Colman et al., 2009; Knop et al., 2009; Ramey \& Ramey, 1998; White, Moffitt, Earls, Robins, \& Silva, 1990). These early difficulties may also create barriers to the provision of effective classroom instruction. For example, school psychologists cite conduct problems as the most challenging form of special needs within mainstream schools (Evans \& Lunt, 2002).

A number of factors have been reported to impact negatively on overall child well-being. Behavioural problems such as defiance, hyperactivity, emotional dysregulation, and poor interpersonal skills, may emerge within the context of a range of interacting risk factors (Arnold et al., 1999; Najman et al., 2000). Dispositional risk factors include impulsivity, difficult temperament, low verbal intelligence, deficits in processing social information, autonomic irregularity, and neurochemical abnormalities (Frick, 2004). Environmental factors include inadequate early childcare and parental supervision (Gibbs, Underdown, Stevens, Newbery, \& Liabo, 2003), adverse social circumstances, economic disadvantage, and impoverished living conditions (Wasserman et al., 2003). Indeed, children who live in areas with high levels of disadvantage or community conflict may present with greater school-based behaviour problems (Coie \& Dodge, 1998; Goeke-Morey et al., 2013). A small number of school and classroom-related factors have also been identified as influential in child psychological health. For example, in a study of middle-school students in Singapore, Chong, Huan, Quek, Yeo, and Ang (2010) noted that student perception of a positive teacher-student relationship was the most significant predictor of school adjustment. Indeed, recent research further indicates that conflict in the classroom and student adjustment are negatively affected when teachers demonstrate unfair patterns of discipline and 'pet-student' preferences (Chin, Lee, \& Liang, 2013).

Inadequate classroom management and negative teacher-student relationships are also associated with higher levels of classroom aggression and poor child adjustment (Kellam, Ling, Rolande, Brown, \& Ialongo, 1998; Raver et al., 
2008). Conduct problems can lead to negative teacher-pupil interaction which, in turn, may hinder the development of appropriate socio-emotional skills in 'at-risk' children (Leflot, van Lier, Onghena, \& Colpin, 2010). Although the importance of a positive classroom dynamic is widely acknowledged, dealing with the needs of numerous children can hinder the quality of teacher-pupil interactions. Thus, class size has also been shown to have a negative relationship with child adjustment (Blatchford, Edmonds, \& Martin, 2003; Finn, Pannozzo, \& Achilles, 2003). Other factors, such as gender, may play a role in determining the quality of school adjustment (Birch \& Ladd, 1997). Overall, classroom quality is vitally important in facilitating child adjustment to school (Barnett, 2002) whilst also helping to promote a positive attitude toward education in the early school years (Hamre \& Pianta, 2001).

The current study was conducted in the Republic of Ireland where school attendance is compulsory from the age of 6 . However, many children begin school at 4 and most 5-year-olds have already entered education (Eurydice Education, Audiovisual \& Cultural Executive Agency, 2009). Schooling in Ireland typically begins at a very young age when compared to most other European countries (OECD, 2004). Only two published prevalence studies on conduct problems in schools have been conducted in Ireland over the last 20 years, which show that $10 \%$ to $11 \%$ of primary school children aged 9 to 10 years have significant levels of emotional disturbance (Porteus, 1991; Williams et al., 2009). Further work by Kiernan et al. (2008) found that almost $56 \%$ of a small sample of socio-economically disadvantaged children in Ireland $(N=89)$ experienced some barriers to school readiness, whilst $11 \%$ were reported to have considerable behavioural and socio-emotional difficulties.

The recent financial crisis in Ireland, as in many other countries, has meant reductions in public spending and in financial investment in primary education. Despite this, a number of initiatives which aim primarily to improve standards in the early childhood care and education sector and to tackle educational disadvantage, remain in place. Access to psychological assessment is provided to all primary schools through the National Educational Psychological Service (NEPS), and the designation of certain primary schools in Ireland as 'disadvantaged' by the Department of Education and Science (DES), has led to greater levels of support for the most disadvantaged children including lower pupil-teacher ratios, special grants, and extra help for pupils. Several of the schools within the current study are located in areas of high economic deprivation. International data show that Ireland has the sixth largest primary school class size $(24.3$ pupils) within the OECD member countries (OECD, 2010), as well as high teacher-pupil ratios, with almost 18 children per teacher. This figure is notably higher than both the European and US average (14.6 and 14.3 children per teacher respectively).

The current study was undertaken as part of an exploratory group-randomized trial designed to evaluate the effectiveness of the Incredible Years Teacher Classroom Management (TCM) programme (Webster-Stratton, Reid, \& 
Hammond, 2004) in Ireland (McGilloway et al., 2010). The principal aim of this initial screening study was to assess the nature and extent of conduct problems in a representative sample of children in the first two years of primary school. The assessment of the level of difficulty experienced in a given classroom is important for many reasons, not least to provide a baseline from which interventions may be assessed (Webster-Stratton \& Lindsay, 1999). The specific objectives of the study were to: (i) document the teacher-reported prevalence of conduct and socio-emotional problems in the first two years of school; (ii) compare the scores to normative national and international scores; (iii) explore the classroom environment, including teachers' perceptions of child discipline in school and strategies used to tackle disordered conduct in the classroom and to promote child adjustment; and (iv) to assess the impact of class size on teacher-reported prevalence of conduct problems.

\section{Method}

\section{Participants and settings}

This study was conducted in 11 primary schools located in the south west of Ireland. Seven of the schools were designated as 'disadvantaged'; eight were located in a city municipality characterized by unusually high levels of social disadvantage, as evidenced by a high concentration of social housing developments (Campbell, 2010). Ongoing violent conflict is also evident in some of the communities where several of these schools are located. Five of these city-based schools were designated as disadvantaged schools. A further two schools were based in towns whilst one was located in a rural community. Two teachers, who were responsible for either a Junior or Senior Infant class (aged 4-7 years) from each of the 11 schools $(N=22)$ participated in the study. Only one of the teacher participants was male, although this is typical of teacher gender representation in infant classes (Drudy, Martin, O’Flynn, \& Woods, 2005). Most teacher participants were aged 25-34 years $(N=15)$; only five were aged between 35-54 years.

A total of 445 children from children in Junior and Senior Infant classes were screened by the 22 teachers. At the time of data collection, children had a mean age of 5.4 years $(\mathrm{SD}=0.71$; range $=3.96$ years $)$. Over half were female $(56 \%, 253 / 445)$, with the sample almost equally divided between Junior and Senior Infant classes (49\% and 51\% respectively). Two-thirds of the children (295/445) were attending mixed sex schools. The number of children in each class ranged from 11-29 (average class size $=20.23$ )

\section{Measures}

The Strengths and Difficulties Questionnaire-Teacher version (SDQ; Goodman, 1997) was used to assess conduct problems and socio-emotional well-being. This is a widely used psychometrically robust inventory developed for use with 4- to 
16-year-olds. A score of 12-15 indicates 'borderline' difficulties, whilst a score of 16-40 represents 'abnormal' difficulties (see www.infosdq.org).

A Teacher Profile Form was developed for this study to allow teachers to detail their perceptions of classroom difficulties in the first instance; this contained a number of open-ended questions. The Teacher Strategies Questionnaire (TSQ; Webster-Stratton, 2005), comprises four subscales to assess: (i) teacher confidence in managing behaviour; (ii) use of classroom management strategies; (iii) perceived utility of used strategies; and (iv) teacher-parent interaction. A further two items were used to assess teacher confidence in managing children's behaviour problems (rated from $1=$ not very confident to $7=$ very confident). The frequency and perceived utility of positive and negative classroom management strategies used, were also assessed using 34 items, each of which was scored on a five-point Likert scale (from $1=$ rarely/never used to $5=$ used very often). Positive strategies include 'giving clear positive instructions' and 'using praise and incentives' whilst negative strategies include 'warning and threatening to send children out of class' and 'singling out children for misbehaviour'.

\section{Results}

\section{Child socio-emotional and behavioural health}

In total, $26 \%$ of children in the sample were reported to have levels of conduct problems and socio-emotional difficulties within the 'borderline/abnormal' range, indicating that a significant proportion of children displayed poor behavioural adjustment. Abnormal levels of hyperactivity were reported by teachers in $18 \%$ of children. Eleven per cent of children were reported to have impaired social behaviour, whilst a further $38 \%$ were reported to be within the 'borderline to abnormal' range with respect to their ratings on the Impact Supplement subscale. These scores show a similar pattern to a British normative sample (Meltzer, Gatward, Goodman, \& Ford, 2000), and indicate that the majority of children in this study were well-adjusted. However, the results of a number of one sample $t$-tests indicated that the mean 'total difficulty' score in the current study was significantly higher than that reported by Meltzer et al. (2000), as were mean scores for 'emotional symptoms', 'hyperactivity' and 'impact supplement' subscales (Table 1). Furthermore, significant differences on all subscales other than 'conduct problems', were identified between this and the most recent comparable Irish study (Williams et al., 2009).

\section{Teachers' perceptions of classroom difficulties and self-reported behavioural management strategies}

Teachers' main concerns regarding child adjustment to school, centred on children failing to start or finish class work, and having difficulty staying on-task. Overall, teachers considered these to be the most challenging aspects of child behaviour in 
Table I. Summary statistics for SDQ scores and norm sample comparisons.

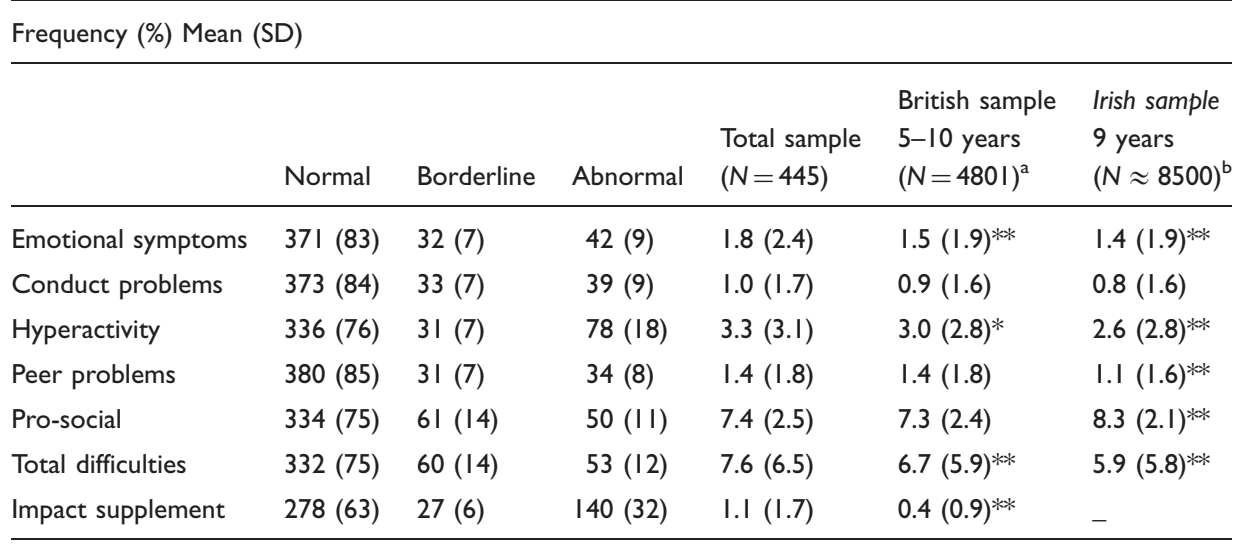

aMeltzer et al. (2000); b'Williams et al. (2009).

$*$ One-sample $t$-test significant at the $p<0.05$ level; **One-sample $t$-test significant at the $p<0.01$ level.

the classroom. However, aggressive and externalizing behaviours were also a source of significant concern. Teachers further cited oppositional behaviours (including inability to deal appropriately with correction) as major disruptions to the classroom environment whilst peer conflict difficulties were also in evidence. A number of key background factors were understood by teachers to impede positive behaviour and appropriate socio-emotional development in the classroom including social disadvantage and poor discipline at home.

Almost three-quarters of the sample (16/22) felt either 'somewhat confident' $(N=6)$ or 'confident' $(N=10)$ in their ability to manage current problems in classroom behaviour. Self-reported teacher confidence showed a moderate negative correlation with the total level of behavioural problems in the class $(r=-0.469$, $p<0.05)$. The most frequently used classroom management strategies involved commenting on good behaviour and using praise and incentives. Teachers' selfreported use of anger management strategies and labelling emotions was comparatively low. Negative strategies such as physical restraint and suspensions were used only rarely, although commenting on inappropriate behaviour was frequently reported. Commenting in a loud voice was also routinely used as a classroom management strategy. Overall, the teacher-reported use of positive strategies, such as praise and incentives, was high $(M=61.29)$, whilst they reported moderate usage of 'negative' classroom management strategies such as shouting, warnings and criticisms $(M=12.88)$.

\section{Class size and conduct problems}

The impact of class size on the prevalence of conduct problems was examined using a one-way analysis of variance (ANOVA). The total sample was divided 
Table 2. Comparison of mean SDQ scores by class size.

\begin{tabular}{|c|c|c|c|c|c|}
\hline & \multicolumn{3}{|l|}{ Mean (SD) } & \multirow[b]{2}{*}{$F$} & \multirow[b]{2}{*}{ Effect size } \\
\hline & $\begin{array}{l}\text { Small class } \\
(N=194)\end{array}$ & $\begin{array}{l}\text { Medium class } \\
(N=139)\end{array}$ & $\begin{array}{l}\text { Large class } \\
(N=1 \mid 2)\end{array}$ & & \\
\hline Emotional symptoms & $1.64(2.4)$ & $\mathrm{I} .73(2.2 \mathrm{I})$ & $2.32(2.62)$ & $3.04 I^{*}$ & 0.01 \\
\hline Conduct problems & $0.99(1.67)$ & $1.23(1.93)$ & $0.68(1.25)$ & $3.406 *$ & 0.01 \\
\hline Hyperactivity & $3.15(3.05)$ & $3.27(3.47)$ & $3.63(2.8)$ & 0.819 & 0.001 \\
\hline Peer problems & $1.12(1.6 \mathrm{I})$ & $1.5(2.02)$ & $1.74(1.64)$ & $3.387^{*}$ & 0.02 \\
\hline Pro-social behaviour & $7.66(2.43)$ & $7.63(2.63)$ & $6.69(2.32)$ & $6.33 * *$ & 0.03 \\
\hline Total difficulties & $7(6.21)$ & $7.73(7.23)$ & $8.37(5.83)$ & 1.65 & 0.01 \\
\hline Impact supplement & $1.28(1.8 \mathrm{I})$ & $1.14(1.6)$ & $0.79(1.55)$ & 3.12 & 0.01 \\
\hline
\end{tabular}

*Significant at the $p<0.05$ level; **Significant at the 0.01 level.

into three groups according to class size: small ( $\leq 20$ pupils); average (21-25 pupils); and large (26-29 pupils). Effect sizes were calculated using eta squared, whereby an effect size of 0.01 denotes a small effect, 0.06 a medium effect, and 0.14 a large effect of the intervention (Cohen, 1988). An analysis based on subscale scores revealed several main effects relating to emotional symptoms $(p=0.049)$, conduct problems $(p=0.034)$, peer problems $(p=0.035)$, and prosocial behaviour $(p=0.002)$ (Table 2$)$. The difference between the class groups with respect to hyperactivity levels was not statistically significant. Post-hoc tests indicated that the mean 'emotional symptoms' score for small classes was significantly different from that of large classes. These classes also differed significantly with respect to mean levels of peer problems and pro-social behaviour, indicating that smaller classes had lower levels of peer conflict and higher levels of positive social behaviour.

A statistically significant effect of class size on the 'total difficulties' mean score was also identified for girls; girls in smaller classes $(N=82)$ were rated as significantly worse, on average, than those in medium $(N=70)$ or large classes $(N=101)$ $(F(2,250)=3.25, p<0.05)$. Similar subscale differences were also found with respect to girls in larger classes who were reported to have significantly higher levels of emotional symptoms $(p=0.49)$, conduct problems $(p=0.039)$, and peer problems $(p<0.001)$ when compared to boys. As the total number of boys in large classes was small $(N=11)$, the medium and large sized classes were merged and an independent sample $t$-test conducted to examine the effect of class size on behavioural problems for boys. No statistically significant differences were found in levels of behavioural and/or socio-emotional problems between boys in small $(N=112)$ and larger classes $(N=80)$. 


\section{Discussion}

This study examined the teacher-reported prevalence of conduct and socio-emotional problems among a sample of Irish children in the first two years of formal education. A secondary aim was to describe the classroom environment and to identify factors which may influence child behaviour within the classroom. Teacher reports indicated that a significant number of children in the current study experienced some conduct and emotional problems and social skills impairment during their first years of formal education. The comparisons with British (Meltzer et al., 2000) and Irish (Williams et al., 2009) samples, which were, albeit inclusive of older children, also show that young children in the current study fared significantly less well in terms of overall social, emotional, and behavioural difficulties. Although this study did not directly examine the effect of socio-economic status on child adjustment to school, a high proportion of children in the current study were attending disadvantaged schools. Thus, our findings are in line with previous research which shows socio-economic disadvantage to be an important risk factor for the development of emotional and behavioural difficulties in young children (Frick \& Morris, 2004; Webster-Stratton \& Hammond, 1998).

Overall, teacher reports in the current study indicated that they regularly face problematic, aggressive, and often unpredictable behaviour in the classroom. Children's disruptive and non-compliant behaviour appeared to be commonplace and was directly and negatively impacting teachers' classroom experience. Frequent behavioural disruptions within the class can overwhelm teachers and impair their ability to teach. However, both positive schooling environments and student-teacher relationships have a favourable influence on child adjustment (Baker, 2006; Warren et al., 2006). It is reassuring to note that teachers in the current study used some positive strategies for managing classroom behaviour and facilitating learning. Raver and colleagues (2008) found that teachers who have better skills in managing disruptive behaviours fared better at preventing disordered conduct in the classroom. Further evidence suggests that children in a well-managed classroom show significantly less aggressive behaviour and spend more time on-task than matched controls in less well-managed classrooms (Kellam et al., 1998). While most teachers in the current study reported feeling confident in their ability to manage behavioural problems, a significant proportion (6/22) indicated that they felt less than confident in their classroom management abilities. Likewise, previous research has noted that teachers feel ill-prepared to manage behavioural problems in the classroom, whilst a significant relationship between teacher confidence and behavioural problems in children, was also reported (Hutchings et al., 2007).

The findings from the current study indicate that class size may impact on the levels of, and challenges in managing, conduct problems and socio-emotional difficulties in the classroom. Previous research has indicated that teachers working in 
smaller classrooms report significantly fewer problems than those in larger classrooms (Finn et al., 2003). Smaller class sizes have also been linked to increased pupil engagement with learning activities (Blatchford et al., 2003). Thus, large class sizes may pose a considerable barrier to adequately addressing the personal and learning needs of 'at risk' children. Interestingly, the effect of class size was significant for girls in the current study, but not for boys. The reasons why girls may fare more poorly in larger classrooms are unclear in the context of this exploratory study. However, previous research has indicated that teachers typically report closer relationships with girls in their classrooms (Birch \& Ladd, 1997) which may, in turn, act as an important protective factor for child adjustment to school. However, in larger classrooms, it may be more difficult for teachers and students to establish such positive relationships. Future research should focus on the effects of school and classroom-related factors on the well-being of children, how these interact with individual differences, and indeed, whether certain groups of children are more likely to fare better in different types of schooling environments.

Teachers' use of strategies such as emotional labelling, problem solving, and anger management were also relatively low in the current study and may indicate that they are less well-equipped than they might otherwise be, to manage conduct problems in the classroom. Likewise, whilst there was moderate use of negative classroom strategies, teachers reported frequent use of some negative strategies (e.g. singling out children for misbehaviour). This is a source of some concern in terms of the potential implications of negative teacher-pupil interaction for both child and teacher outcomes, as well as the overall classroom environment (Chong et al., 2010; Hamre \& Pianta, 2001). These findings are in line with those of AkinLittle, Little, and Laniti, (2007) who also noted a reliance on negative classroom management strategies amongst a sample of both Greek and American teachers, despite high levels of positive reinforcement.

The current study is limited by the absence of information on socio-economic status or parent-child relationships. These factors can contribute significantly to child well-being and can be important influences on adjustment to, and behaviour in, school. These factors are also likely to interact in complex ways with children's experiences of school and their classroom environment. Disentangling the effects of multiple potentially interacting factors presents researchers with many challenges. Future studies that examine a range of factors, including those with a focus on classroom management, may provide a clearer picture of the main contributors to the social, emotional, and behavioural well-being of children in classrooms. However, whilst teacher reports may be influenced by child characteristics, as well as their academic performance or attitudes towards parents (Coie, 1990), it has been argued that teachers provide a more reliable and less biased report of child behaviour than parents (Webster-Stratton \& Lindsay, 1999). This is particularly so within the classroom context. Arguably therefore, teacher reports provide an appropriate and valuable source of information. 


\section{Implications}

The findings of this study provide a snapshot of the numerous challenges facing teachers of children with conduct problems and socio-emotional difficulties and the extent to which they use appropriate classroom management strategies. Quality of life in the classroom is increasingly recognized for its importance in child adjustment (Barnett, 2002; Jennings \& Greenberg, 2009; Reyes, Brackett, Rivers, White, \& Salovey, 2012) and yet school and classroom characteristics, and their contribution to the mental health and personal development of young learners, have received relatively little research attention. Providing good quality early education and improving the socio-emotional skills of at-risk children as early as possible, can impact positively on child cognitive growth, academic success, and ultimately promote adult social and emotional adjustment (Barnett, 2002). Developing partnerships between teachers, parents, and school psychologists (and other psychological service providers) can also assist in the implementation of strategies to manage child behavioural difficulties and improve the general classroom environment (Greenberg, 2010).

The principle of early childhood intervention to foster well-being and school adjustment is well-established (Chong et al., 2010; Hamre \& Pianta, 2001). However, in order to effectively target emotional and behavioural difficulties in the classroom, it is necessary to first ascertain the nature and extent of the problems that teachers encounter on a daily basis. Referrals to school psychologists are often the first step for teachers with concerns about students' conduct problems and socio-emotional well-being. Early warning systems which involve collaboration between parents, teachers, and mental health professionals, particularly school psychologists, must be implemented in order to provide optimal outcomes for children at risk. As shown by previous research (Allen, 2011), time is critical — with early intervention offering the best outcomes. The findings reported here, enhance our understanding of the emotional and behavioural needs of young, mainly disadvantaged children at the beginning of their school career and provide important baseline information relating to the development and implementation of targeted intervention programmes. Our results also provide a useful benchmark against which to monitor and assess the effectiveness of interventions such as the Incredible Years Teacher Classroom Management Programme (Webster-Stratton et al., 2004), which may be implemented by teachers, school psychologists, or other trained professionals. Our further work in this area is described elsewhere (McGilloway et al., 2010; NiMhaille et al., available from the corresponding author upon request). Collectively, the findings of this research programme suggest a need for appropriate evidence-based support and resources for children with conduct problems and socio-emotional difficulties, as well as for their educators.

Given the importance of positive teacher-pupil relationships and of socioemotional and behavioural well-being in the classroom (as well as more generally), there is a need to focus on preparing both educators and school psychologists to deal with aversive child behaviour and to equip them with the skills to maximize 
child adjustment to school. Evidence-based early interventions which aim to improve teacher self-efficacy and classroom management skills are important and may potentially benefit pupil adjustment. School psychologists are ideally placed to deliver such training programmes (Hutchings et al., 2012) and the timely delivery of classroom management training to teachers and (where possible) teaching assistants (e.g. via school psychological services), could provide far-reaching benefits and potentially reduce the need for costly, intensive interventions at a later stage. The provision of these kinds of supports in educational settings may help to create better learning environments whilst also promoting child social and emotional growth and adjustment.

\section{Note}

This study was funded by Archways Ltd (www.archways.ie) with financial support from the Atlantic Philanthropies.

\section{References}

Akin-Little, K. A., Little, S. G., \& Laniti, M. (2007). Teachers' use of classroom management procedures in the United States and Greece: A cross-cultural comparison. School Psychology International, 28, 53-62.

Allen, G. (2011). Early Intervention: Next Steps. Cabinet Office: London.

Arnold, D. H., Ortiz, C., Curry, J. C., Stowe, R. M., Goldstein, N. E., Fisher, P. H., Zeljo, A., ... Yershova, K. (1999). Promoting academic success and preventing disruptive behavior disorders through community partnership. Journal of Community Psychology, 27, 589-598.

Baker, J. A. (2006). Contributions of teacher-or arechild relationships to positive school adjustment during elementary school. Journal of School Psychology, 44, 211-229.

Barbarin, O. A. (2007). Mental health screening of preschool children: Validity and reliability of ABLE. American Journal of Orthopsychiatry, 77, 402-418.

Barnett, W. S. (2002). Early childhood education. In A. Molnar (Ed.), School reform proposals: The research evidence (pp. 1-26). Greenwich, CT: Information Age Publishing.

Birch, S. H., \& Ladd, G. W. (1997). The teacher-child relationship and children's early school adjustment. Journal of School Psychology, 35, 61-79.

Blair, C., \& Diamond, A. (2008). Biological processes in prevention and intervention: The promotion of self-regulation as a means of preventing school failure. Development and Psychopathology, 20, 899-911.

Blatchford, P., Edmonds, S., \& Martin, C. (2003). Class size, pupil attentiveness and peer relations. British Journal of Educational Psychology, 73, 15-36.

Campbell, L. (2010). Responding to gun crime in Ireland. The British Journal of Criminology, 50, 414-434.

Chin, S., Lee, J., \& Liang, T. (2013). Does the teacher's pet phenomenon inevitably cause classroom conflict? Comparative viewpoints of three pet-student groups. School Psychology International, 34(1), 3-16.

Chong, W. H., Huan, V. S., Quek, C. L., Yeo, L. S., \& Ang, R. P. (2010). Teacher-student relationship: The influence of teacher interpersonal behaviours and perceived beliefs about teachers on the school adjustment of low achieving students in Asian middle schools. School Psychology International, 31, 312-328. 
Cohen, J. (1988). Statistical power analysis for the behavioral sciences. Hillsdale, NJ: Lawrence Erlbaum.

Coie, J. D. (1990). Toward a theory of peer rejection. In S. R. Asher, \& J. D. Coie (Eds.), Peer rejection in childhood (pp. 365-401). Cambridge: Cambridge University Press.

Coie, J., \& Dodge, K. (1998). Aggression and antisocial behavior. In N. Eisenberg (Ed.), Handbook of child psychology, volume 3: Social, emotional, and personality development (pp. 779-862). New York, NY: Wiley.

Colman, I., Murray, J., Abbott, R., Maughan, B., Kuh, D., Croudace, T.,...Jones, P. (2009). Outcomes of conduct problems in adolescence: Forty-year follow-up of a national cohort. British Medical Journal, 338, a2981.

Drudy, S., Martin, M., O'Flynn, J., \& Woods, M. (2005). Men and the classroom: Male teachers in today's primary school. Oxford: Routledge.

Eurydice Education, Audiovisual \& Culture Executive Agency. (2009). Key data on education in Europe, 2009. Brussels: EACEA.

Evans, J., \& Lunt, I. (2002). Inclusive education: Are there limits? European Journal of Special Needs Education, 17, 1-14.

Evans, J., Harden, A., Thomas, J., \& Benefield, P. (2003). Support for pupils with emotional and behavioural difficulties (EBD) in mainstream primary classrooms: A systematic review of the effectiveness of interventions. Research Evidence in Education Library. London: EPPI-Centre, Social Science Research Unit, Institute of Education.

Finn, J. D., Pannozzo, G. M., \& Achilles, C. M. (2003). The 'why's' of class size: Student behaviour in small classes. Review of Educational Research, 73, 321-368.

Frick, P. J. (2004). Developmental pathways to conduct disorder: Implications for serving youth who show severe aggressive and antisocial behaviour. Psychology in the Schools, 41, 823-834.

Frick, P. J., \& Morris, A. S. (2004). Temperamental and developmental pathways to conduct problems. Journal of Clinical Child and Adolescent Psychology, 33, 54-68.

Gibbs, J., Underdown, A., Stevens, M., Newbery, J., \& Liabo, K. (2003). Group-based parenting programmes can reduce behaviour problems of children aged 3-12 years. Evidence Nugget April 2003. London: What Works for Children.

Goeke-Morey, M. C., Taylor, L. K., Merrilees, C. E., Cummings, E. M., Cairns, E., \& Shirlow, P. (2013). Adolescents' educational outcomes in a social ecology of parenting, family, and community risks in Northern Ireland. School Psychology International, 34(3), 243-256.

Goodman, R. (1997). The strengths and difficulties questionnaire: A research note. Journal of Child Psychology and Psychiatry, 38, 581-586.

Greenberg, M. (2010). School-based prevention: Current status and future challenges. Effective Education, 2, 27-52.

Hamre, B. K., \& Pianta, R. C. (2001). Early teacher-child relationships and the trajectory of children's school outcomes through eighth grade. Child Development, 72, 625-638.

Hutchings, J., Bywater, T., Gridley, N., Whitaker, C. J., Martin-Forbes, P., \& Gruffydd, S. (2012). The Incredible Years therapeutic social and emotional skills programme: A pilot study. School Psychology International, 33(3), 285-293.

Hutchings, J., Daley, D., Jones, K., Martin, P., Bywater, T., \& Gwyn, R. (2007). Early results from developing and researching the Webster-Stratton Incredible Years Teacher Classroom Management Programme in North West Wales. Journal of Children's Services, 2, 15-26. 
Jennings, P. A., \& Greenberg, M. (2009). The pro-social classroom: Teacher social and emotional competence in relation to student and classroom outcomes. Review of Educational Research, 79, 491-525.

Kellam, S. G., Ling, X., Rolande, M., Brown, H., \& Ialongo, N. C. (1998). The effect of level of aggression in the first grade classroom on the course and malleability of aggressive behavior into middle school. Development and Psychopathology, 12, 165-185.

Kiernan, G., Axford, N., Little, M., Murphy, C., Greene, S., \& Gormley, M. (2008). The school readiness of children living in a disadvantaged area in Ireland. Journal of Early Childhood Research, 6, 119-144.

Knop, J., Penick, E. C., Nickel, E. J., Mortensen, E. L., Sullivan, M. A., Murtaza, S., Jensen, P., Manzardo, A. M.,... Gabrielli, W. F. Jr (2009). Childhood ADHD and conduct disorder as independent predictors of male alcohol dependence at age 40 . Journal of Studies on Alcohol and Drugs, 70, 169-177.

Ladd, G. W. (1990). Having friends, keeping friends, making friends, and being liked by peers in the classroom: Predictors of children's early school adjustment?. Child Development, 61, 1081-1100.

Leflot, G., van Lier, P., Onghena, P., \& Colpin, H. (2010). The role of teacher behavior management in the development of disruptive behaviors: An intervention study with the Good Behavior Game. Journal of Abnormal Child Psychology, 38, 869-882.

McGilloway, S., Hyland, L., Ni Mhaille, G., Lodge, A., O’Neill, D., Kelly, P., Leckey, Y., ... Donnelly, M. (2010). Positive classrooms, positive children: A randomised controlled trial to investigate the effectiveness of the Incredible Years Teacher Classroom Management Programme in an Irish context. Dublin: Archways.

Meltzer, H., Gatward, R., Goodman, R., \& Ford, F. (2000). Mental health of children and adolescents in Great Britain. London: The Stationery Office.

Najman, J. M., Williams, G. M., Nikles, J. M. B., Spence, S., Bor, W., O'Callaghan, M., LeBrocque, R.,... Andersen, M. J. (2000). Mothers' mental illness and child behaviour problems: Cause-effect association or observation bias? Journal of the American Academy of Child and Adolescent Psychiatry, 39, 592-602.

Organisation for Economic Co-operation and Development (OECD). (2004). Early childhood education and care policy: Country note for Ireland. Paris: OECD.

Organisation for Economic Co-operation and Development (OECD). (2010). Education at a Glance. Paris: OECD.

Porteus, M. A. (1991). A study of behavioural and emotional problems in Irish primary. school children. The Irish Journal of Psychology, 12, 304-315.

Ramey, C. T., \& Ramey, S. L. (1998). Early intervention and early experience. American Psychologist, 53, 109-120.

Raver, C. C., Jones, S. M., Li-Grining, C. P., Metzger, M., Champion, K. M., \& Sardin, L. (2008). Improving preschool classroom processes: Preliminary findings from a randomized trial implemented in Head Start settings. Early Childhood Research Quarterly, 23, 10-26.

Reyes, M. R., Brackett, M. A., Rivers, S. E., White, M., \& Salovey, P. (2012). Classroom emotional climate, student engagement and academic achievement. Journal of Educational Psychology, 104, 700-712.

Stephen, C., \& Cope, P. (2003). Moving on to primary 1: An exploratory study of the experience of transition from pre-school to primary (Insight 3). Edinburgh: Scottish Executive.

Warren, J. S., Bohanon-Edmonson, H. M., Turnbull, A. P., Sailor, W., Wickham, D., Griggs, P.,... Beech, S. E. (2006). School-wide positive behaviour support: Addressing 
behaviour problems that impede student learning in education. Educational Psychology Review, 18, 187-198.

Wasserman, G. A., Keenan, K., Tremblay, R. E., Coie, J. D., Herrenkohl, T. I., Loeber, R., et al. (2003). Risk and protective factors of child delinquency (NCJ193409). Washington, DC: US Department of Justice, Office of Justice Programs, Office of Juvenile Justice and Delinquency Prevention.

Webster-Stratton, C. (2005). Teacher strategies questionnaire. Retrieved from http://www. incredibleyears.com/Measures/tsq-scoring.pdf.

Webster-Stratton, C., \& Hammond, M. (1998). Conduct problems and level of social competence in Head Start Children: Prevalence, pervasiveness, and associated risk factors. Clinical Child and Family Psychology Review, 1, 101-124.

Webster-Stratton, C., \& Lindsay, D. W. (1999). Social competence and conduct problems in young children: Issues in assessment. Journal of Clinical Child Psychology, 28, 25-43.

Webster-Stratton, C. S., Reid, M. J., \& Hammond, M. (2004). Treating children with earlyonset conduct problems: Intervention outcomes for parent, child, and teacher training. Journal of Clinical Child and Adolescent Psychology, 33, 105-124.

White, J. L., Moffitt, T. E., Earls, F., Robins, L., \& Silva, P. A. (1990). How early can we tell? Predictors of childhood conduct disorder and delinquency. Criminology, 28, 507-533.

Williams, J., Greene, S., Doyle, E., Harris, E., Layte, R., McCoy, S., McCrory, C., Murray, A., Nixon, E., McDowd, T., O’Moore, M., Quail, A., Smyth, E., Swords, L.,... Thornton, M. (2009). Growing up in Ireland: The lives of nine-year olds. Dublin: The Stationery Office.

\section{Author biographies}

Lynda Hyland, MSc, is a Doctoral Fellow at NUI Maynooth. Her research interests include teacher classroom management, social and health inequalities, and behaviour change intervention research.

Grainne Ní Mháille, PhD, is a Research Fellow at NUI Maynooth. Her research interests include child health, family relationships, prevention and early intervention, research methodology, and qualitative psychology.

Anne Lodge, PhD, is the Principal of the Church of Ireland College of Education, Dublin. Her research interests include the sociology of education and teacher education.

Sinead McGilloway, PhD, CPsychol, CSci, AFBPS, is a Senior Lecturer in Psychology and Director of the Mental Health and Social Research Unit at NUI Maynooth. Her research interests include child and adult mental health, evaluation and intervention research and the health and social care needs of vulnerable or socially excluded children and adults. 